\title{
Commentary
}

\section{Geffen Faculty Highlight Concerns Linking CAIM and Conventional Researchers at UCLA Symposium}

\author{
Elizabeth H. Logue \\ UCLA Center for East West Medicine, Santa Monica, CA 90404, USA
}

\begin{abstract}
David Geffen School of Medicine faculty, representing a wide range of disciplines, engaged speakers nationally known for their expertise on complementary, alternative and integrative medicine (CAIM) and its investigation at a January, 2008 symposium on the campus of the University of California, Los Angeles. The forum was created to educate the UCLA Institutional Review Board (IRB), and lively participation by School of Medicine faculty helped bring IRB members up to speed on controversies surrounding CAIM research. The symposium demonstrated that academics who are neither proponents nor detractors of CAIM can facilitate cross talk between opposing camps, elucidating questions important to its evaluation by those charged with protecting research subjects. It also brought attention to the universality of quandaries facing CAIM investigators and to the ingenuity with which they have addressed many of them.
\end{abstract}

Keywords: attitudes towards CAM - cost-benefit analysis - double blind randomized controlled clinical trial - experimental study - quality of life trials

'Science of CAIM: What's Next for Complementary, Alternative and Integrative Medical Research?' a UCLA symposium meant to acquaint Institutional Review Board (IRB) members with controversies surrounding CAIM's investigation focused first on regulation (1). Thanks largely to input from David Geffen School of Medicine faculty, however, the January, 2008 event blossomed into a thoughtful airing of a broad range of questions facing both CAIM and conventional researchers. Dr Daniel Cherkin of Group Health, Seattle, gave a cogent introduction to the topic. Noted CAIM critic, Dr Donald Marcus of Baylor College of Medicine and Dr John Longhurst, Director of the Susan Samueli Center for Integrative Medicine at the University of California, Irvine then began by criticizing government regulatory efforts. Dr Ary Goldberger, Director of the Margret \& H.A. Rey Institute for Nonlinear Dynamics in Medicine at Harvard University followed, providing a

For reprints and all correspondence: Elizabeth H. Logue, UCLA Center for East West Medicine, 2428 Santa Monica Boulevard, Suite 208, Santa Monica, CA 90404, USA. Tel: (310) 998-9118; Fax: (310) 829-9318; E-mail: elogue@mednet.ucla.edu glimpse of where CAIM may be heading in describing his own research. Then, UCLA faculty proceeded to give the event its unique character with their questions and comments, demonstrating equal interest in policy and scientific concerns. The panelists included Distinguished Professor of Neurobiology and Editor in Chief of $e C A M$, Edwin L. Cooper; noted cancer researcher, Dr Patricia Ganz; Professor of Neurology, Radiology, Psychiatry and Biomedical Physics, Mark S. Cohen; geriatrics substance abuse expert, Dr Alison Moore and pediatric pain investigator, Dr Jennie Tsao. Although time prohibited an in-depth exploration of most of the questions raised, many were thought provoking and deserve further consideration.

Some panelists homed in on the role played by politics in the evolution of National Institutes of Health (NIH) Centers. In this connection, it should be noted that political considerations are crucial in determining health priorities. In the CAIM world, advocates of traditional medicine are sometimes at odds with those whose focus is the complementary health practices of the more affluent. Such conflict is generally salutary, the successes of AIDS 
activists providing just one example of its potential $(2,3)$. Irrespective of the role of other stakeholders, the scientific community will always play a leading part in determining the direction of NIH. One panelist's contention that scientists tend to band together in a closed, mutually reinforcing fraternity thus merits comment. Like politics, science is socially constructed and compelling arguments suggest that it is positivistic and may therefore be ill equipped to accommodate true innovation (4). It is worth considering whether we need proponents of unorthodox ideas simply to oppose any such tendencies.

Another panelist lent support to arguments about conservatism in science, citing peers' unwillingness to look at evidence linking the mind and body. Such skepticism is especially ironic, given that the 'humors' paradigm held sway in the West long after scientists elsewhere had turned to what more closely resembles modern experimental methodology (5). Today there is convincing research showing that expectations influence outcomes and that placebo analgesia leads to brain changes (6-8). Rational people may disagree on the centrality of nonspecific effects or on the prescription of 'inert' treatment, but it is a matter of concern when prejudice prevents a fair hearing for even well grounded work on such questions.

While speakers criticized the National Center for Complementary and Alternative Medicine (NCCAM) for funding scientifically unsound research, some panelists took exception to that critique. One noted that taxpayers approve faith-based initiatives, implying that orthodox notions of plausibility should not necessarily predominate at NIH. This is a persuasive argument, but it is important to remember that the scientific community's view of plausibility and how it should be determined is, itself, in flux. For example, while the randomized trial has played an important role, not least in providing an impersonal method of assessment for modern, bureaucratic medicine (3), its pre-eminent position has come into question. This occurs as complexity science yields tools better able to capture the effects of actual medical practice. Theoretical physics, meanwhile, continues to attend closely to expert opinion (3). Perhaps medicine will look to such examples as it reconsiders the status of the 'lesser' forms of evidence. Scientists are also revisiting the question of the order in which studies should be undertaken. Because CAIM is already used widely, many support investigation of effectiveness before mechanism of action (9-12). While some in academic medicine are uncomfortable with such change, clinicians are pragmatic. MDs willingly used aspirin long before learning how it worked and are likely aware that there is little good evidence for many of the decisions they must make $(13,14)$. Whatever they may think of its scientific plausibility, medical doctors, like average citizens, have clamored for information on CAIM (9). One UCLA panelist suggested that a natural 'winnowing' process would ultimately succeed in identifying therapies of real value. This makes sense and an analysis of the approach of others on the same path could help expedite the process. The Hong Kong Hospital Authority uses knowledge mapping to look for areas in which biomedicine has proved weak but CAIM therapies show promise. This may yield opportunities for important collaborative research (15). Reimbursement is based on safety, effectiveness and cost. Any means of speeding up the identification of superior treatments - thus, their availability - is worth pursuing $(16,17)$.

Some CAIM modalities merit study not because they have been identified by means of informatics but simply because they are used regularly by millions. As one 'Science of CAIM' participant remarked, what Americans call 'complementary' and 'alternative' is neither for many. It is sometimes suggested that those using traditional medicine do so because they have no choice. It is ethnocentric to assume inferiority, however, especially given that some traditional medical practices are clearly associated with good health, as one conferee noted. Investigating unconventional medicine does present unique challenges, though, including the problem of paradigm-appropriate design. If, for example, a belief system posits bodily 'hubs', by which treatment affects many targets, it may be necessary to devise new outcomes to test its claims. Unfortunately, there is a dearth of validated outcome measures for CAIM, today $(18,19)$. In dealing with such shortcomings, investigators have found much that may prove valuable to medical science as a whole. For example, methods devised to examine multiple variables within whole systems can inform studies of effectiveness $(11,20)$. As we begin to understand the multiplicity of factors implicated in healing, targeted, cost-effective treatments follow $(21,22)$.

While there may be consensus regarding the need to look at the many contributors to illness and recovery, UCLA participants suggested that when it comes to whole systems of medicine, those elements should not be studied piecemeal. Western science has operated in a reductionistic fashion for some two centuries, but CAIM researchers have asserted that applying conventional methods to whole systems is similar to trying to understand how a computer functions by smashing it and examining the pieces. Small effect sizes for the subunits of such systems suggest that this is an apt metaphor (10). To understand complexity in any form, including multimodal biomedical practice, it is crucial to be aware of the interaction among parts and emergent properties $(11,23-25)$. We now know the importance of the interplay among causes of gene expression (18). Likewise, to understand complex, chronic disease, looking at many factors simultaneously may be critical (22). For example, Ahn has suggested that with diabetes we must comprehend the interplay among inflammation, cortisol, leptin, body mass index and so forth (26). The ultimate question with respect to how parts of a multi-faceted system affect one another, though, is what delimits the system. Does it include friends, the health practitioner, the environment or particular host factors? $(18,27)$ What else must be included? NCCAM is taking on the challenge of 
devising new methods to study biological complexity as well as complex systems, recognizing the need to look at them holistically, so some answers to those questions are likely to be forthcoming $(28,29)$.

One member of UCLA's faculty pointed out that measurement instruments may not be sensitive enough to detect CAIM's effects, which highlights the problem of how to get a fuller picture of the experience patients report, whether of whole-system treatment or of lesscomprehensive alternative therapy. Measures of transformational change, provider/patient match and other factors making a single intervention differentially effective could be useful $(25,30-32)$. To capture dynamism, it might help to employ adaptive and sequential decisionmaking study designs $(21,33,34)$. Various life enhancing effects of CAIM could be evaluated using qualityadjusted life years, which also give a sense of cost effectiveness $(17,35)$. Individualization of treatment is another factor commonly implicated in positive outcomes for CAIM patients. As a focus of investigation, it has the additional advantage that it could lead to a reduction in the complications and waste occurring with generalization from homogeneous, highly responsive subjects $(10,14,26,36)$. Today, biomedicine tries to target therapy based on organ function, hormone status, genomics and proteomics, and 'personalizing' medicine is a major NIH goal $(18,22,37)$. Meanwhile, CAIM researchers champion studies looking at within-subject change and have used informatics to track individualized regimens $(22,38,39)$. Capturing the effects of patient-centered therapy will not only help bridge the gap between negative studies and positive patient reports but has great potential as an area of cooperation between mainstream and CAIM investigators as well.

While there are already some good, albeit underused means of capturing patients' experience of CAIM, a panelist's question as to how to handle small observational studies brings up the fact that numerous technical difficulties remain for would be investigators. NCCAM has specifically addressed the subject of small studies, but what is the best way to correct for differences among providers offering the same treatment or the optimum dose for various parts of a whole system? In order to accommodate prevailing conventions, is it best to look at multimodal treatments together, then to examine them as parts are removed-or will doing so corrupt results irretrievably? $(10,25)$ As the field matures, organizations such the International Society for Complementary Medicine Research can be expected to develop guidelines addressing these and other problems involving design, methodology and data analysis.

By inviting the commentary of persons highly critical of CAIM research and regulation, 'Science of CAIM' succeeded in amplifying concerns underlying IRB prejudice, the existence of which has been suggested by NCCAM and CAIM leaders $(29,40)$. This, in itself, was a valuable achievement. The contribution of UCLA faculty was particularly noteworthy, however, due to the breadth of its implications. Looking further into questions raised by the panelists, it becomes apparent that CAIM scientists are playing a pioneering role with respect to problems that have stumped investigators of all persuasions (41-43). Lively discussion of issues such as scientific plausibility, paradigm-appropriate design and the research agenda likely raised awareness of the common ground between CAIM and mainstream science not only among IRB members in attendance but also among stakeholders in many of the Geffen School's academic departments. Civil but impassioned dialogue involving persons holding strong, divergent views is in the best tradition of liberal education and can break impasses where other means fail. Forward thinking institutions should consider following UCLA's lead, creating forums where CAIM and mainstream scientists can hash out responses to challenges both face together.

\section{Acknowledgments}

Many thanks to Dr Roberto Peccei, Vice Chancellor for Research at UCLA, for his support of 'Science of CAIM' and to Center for East West Medicine personnel including Executive Administrator, Sue Fan, and Director, Dr Ka-Kit Hui. Thanks as well to Professors Emeran Mayer, Margaret Stuber and Edwin Cooper and to IRB Director, Judy Brookshire, all of UCLA for their help with groundwork for the symposium. I am also indebted to Dr Jonathan Berman and Dr Laura Lee Johnson of NCCAM, Professors Mikel Aickin and Iris Bell of the University of Arizona and Dr Aviad Haramati of Georgetown University who provided valuable background on the controversies the symposium addressed.

\section{References}

1. Logue E. 'The science of CAIM: what's next for complementary, alternative and integrative medical research?' Evid Based Complement Altern Med 2008. doi: 10.1093/ecam/nen028. Advance access published 5 February 2008.

2. Bodeker G. Lessons on integration from the developing world's experience. $\mathrm{Br}$ Med $J$ 2001;322:164-7.

3. Dehue T. Testing treatments, managing life: on the history of randomized clinical trials: Harry M. Marks, 'The Progress of Experiment: Science and Therapeutic Reform in the United States, 1900-1990'. Hist Human Sci 1999;12:115-24.

4. Kuhn T. The Structure of Scientific Revolutions. University of Chicago Press, 1962.

5. Chiappelli F, Prolo P, Cajulis OS. Evidence-based research in complementary and alternative medicine I: history. Evid Based Complement Altern Med 2006;2:453-8.

6. Linde K, Witt C, Streng A, Weidenhammer W, Wagenpfeil S, Brinkhaus B, et al. The impact of patient expectations on outcomes in four randomized controlled trials of acupuncture in patients with chronic pain. Pain 2007;128:264-71.

7. Vase L, Pittersen, G. Do placebo effects exist? If so, how can we use them? Abstract of Presentations. Full Program and Abstract Book. Third Annual Congress on Complementary Medicine Research. Sydney: International Society for Complementary Medicine Research, 2008, 025, 088. 
8. Moerman D, Jonas W. Deconstructing the placebo effect and finding the meaning response. Ann Intern Med 2002;36:471-6.

9. Fontanarosa P. Publication of complementary and alternative medical research in mainstream biomedical journals. $J$ Altern Complement Med 2001;7:139-43.

10. Fonnebo V, Grimsgaard S, Walach H, Ritenbaugh C, Norheim A, MacPherson $\mathrm{H}$, et al. Researching complementary and alternative treatments - the gatekeepers are not at home. BMC Med Res Methodol 2007;7:7.

11. Boon H, Macpherson H, Fleishman S, Grimsgaard S, Koithan M, Norheim A, et al., Evaluating complex healthcare systems: a critique of four approaches. Evid Based Complement Altern Med 2007:4:279-85.

12. Berman J, Straus S. Implementing a research agenda for complementary and alternative medicine. Annu Rev Med 2004;55:239-54.

13. Smith G, Pell J. Parachute use to prevent death and major trauma related to gravitational challenge: systematic review of randomised controlled trials. Br Med J 2003;327:1459-61.

14. Feinstein A, Horowitz RI. Problems in the 'evidence' of evidencebased medicine. Am J Med 1997;103:529-35.

15. Wong V, Feichau P. Linking research, policy and action: evidencebased complementary and alternative medicine. Healthc Manage Forum 2006;9:21-6.

16. Fontanarosa P, Lundberg G. Alternative medicine meets science. JAMA 1998;280:1618-9.

17. Committee on the Use of Complementary and Alternative Medicine by the American Public. Institute of Medicine. Contemporary Approaches to Evidence of Treatment Effectiveness: a Context for CAM Research. Washington, DC: National Academies Press, 2005.

18. Bell I, Koithan M. Models for the study of whole systems. Integrative cancer therapies. Integr Cancer Ther 2006;5:293-307.

19. Chiappelli F, Prolo P, Rosenblum M, Edgerton M, Cajulis OS. Evidence-based research in complementary and alternative medicine II: the process of evidence-based research. Evid Based Complement Altern Med 2006:3:3-12.

20. Depp C, Lebowitz BD. Clinical trials: bridging the gap between efficacy and effectiveness. Int Rev Psychiatry 2007;19:531-9.

21. Berry, D. Innovative Statistical Designs for Clinical Trials. Retrieved from NIH Roadmap for Medical Research. Bridging the Gap Between Preclinical and Clinical Evaluation of Therapeutic Candidates. Available at: http://nihroadmap.nih.gov/molecularli braries/workshop2007/abstracts/berry.asp (Accessed May 13, 2008).

22. Cheng Y. Will Traditional Chinese Medicine practices and pharmaceuticals have [a] role in future medicine and what will it take to globalize? Paper presented at: Third Annual Congress on Complementary Medicine Research, 2008 March 29-31, Sydney, Australia.

23. Goldberger A. Complex systems. Proc Am Thorac Soc 2006;3:467-71.

24. Ahn A, Tewari M, Poon C, Phillips R. The limits of reductionism in medicine: could systems biology offer an alternative? PLoS Med 2006;3:e208.

25. Aickin M, Bell I, Elder C, Fonnebo V, Lewith G, Ritenbaugh C, et al. Methodological challenges in whole systems research. J Altern Complement Med 2006;12:843-50.

26. Ahn A, Tewari M, Poon C, Phillips R. The clinical applications of a systems approach. PLoS Med 2006;3: e209.
27. Aickin M. Conceptualization and analysis of mechanistic studies. J Altern Complement Med 2007;13:51-8.

28. Briggs JP. Message from the Director. Retrieved from Director's Page, National Center for Complementary and Alternative Medicine website. Available at: http://nccam.nih.gov/about/director (Accessed May 18, 2008).

29. National Center for Complementary and Alternative Medicine. Expanding Horizons of Health Care Strategic Plan 2005-2009. U.S. Department of Health and Human Services, 2005.

30. Bell I, Caspi O, Schwartz G, Grant K, Gaudet T, Rychener D, et al. Integrative medicine and systemic outcomes research: issues in the emergence of a new model for primary health care. Arch Intern Med 2002;162:133-40.

31. Verhoef M. News from the International Society for Complementary Medicine Research. J Altern Complement Med 2007; 13:477-8.

32. Caspi O, Bell I. One size does not fit all: aptitude $\mathrm{x}$ treatment interaction (ATI) as a conceptual framework for complementary and alternative medicine outcome research. Part 1-what is ATI research? J Altern Complement Med 2004;10:580-6.

33. Collins, LM, Murphy S, Bierman KL. (2004). A conceptual framework for adaptive preventive interventions. Prev Sci 2006;5:185-96.

34. Murphy S, Oslin D, Rush A, Zhu J. Methodological challenges in constructing effective treatment sequences for chronic psychiatric disorders. Neuropsychopharmacology 2007;32:257-62.

35. Bodecker G. The increasing global use of traditional, complementary and alternative medicine (TCAM). Paper presented at: Third Annual Congress on Complementary Medicine Research, March 29-31 2008, Sydney, Australia.

36. Meldrum ML. A brief history of the randomized controlled trial. From oranges and lemons to the gold standard. Hematol Oncol Clin North Am 2000;14:745-60, vii.

37. Zerhouni E. The Promise of Personalized Medicine. Retrieved from NIH Medline Plus, Winter 2007. Available at: http://www.nih.gov/ about/director/interviews/NLMmagazinewinter2007.pdf.Accessed May 13, 2008.

38. Aickin M. Participant-centered analysis in complementary and alternative medicine comparative trials. J Altern Complement Med 2003;9:949-57.

39. Ernst E. Methodological aspects of Traditional Chinese Medicine (TCM). Ann Acad Med Singapore 2006;35:773-4.

40. Dalen JE. Is integrative medicine the medicine of the future? A debate between Arnold S. Relman, MD, and Andrew Weil, MD. Arch Intern Med 1999;159:2122-6.

41. Lewith GT, Verhoef MJ. The international society for complementary medicine research (ISCMR): the way forward. Evid Based Complement Altern Med 2006;3:157-8.

42. Lewith G, Verhoef M, Koithan M, Zick SM. Developing CAM research capacity for complementary medicine. Evid Based Complement Altern Med 2006;3:283-9.

43. Murillo H, Reece EA, Snyderman R, Sung NS. Meeting the challenges facing clinical research: solutions proposed by leaders of medical specialty and clinical research societies. Acad Med 2006;81:107-12.

Received June 12, 2008; accepted June 20, 2008 


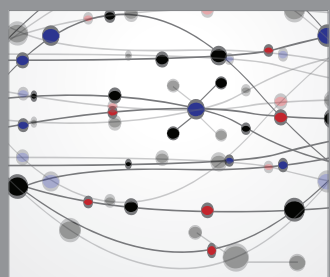

The Scientific World Journal
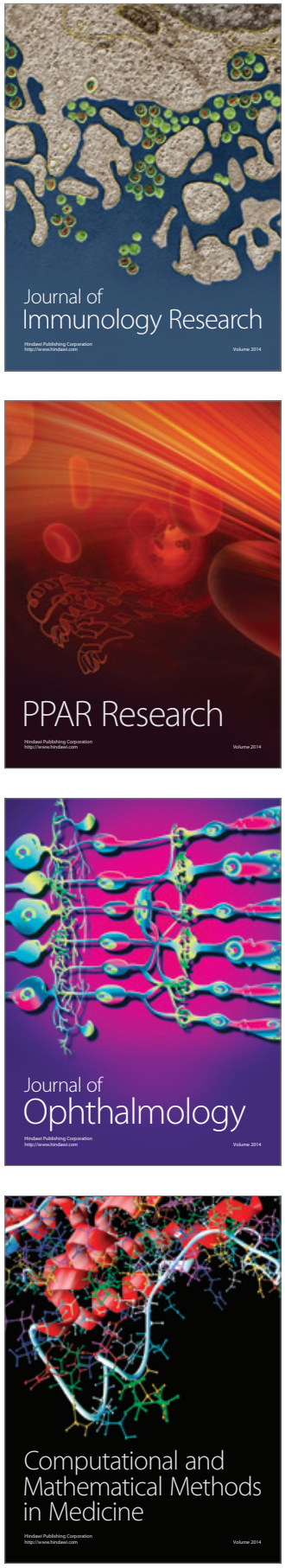

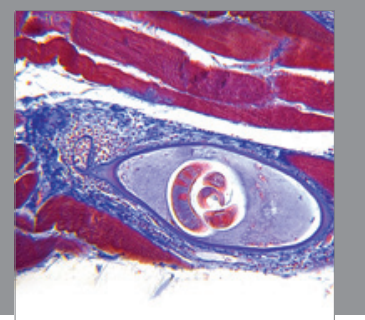

Gastroenterology

Research and Practice
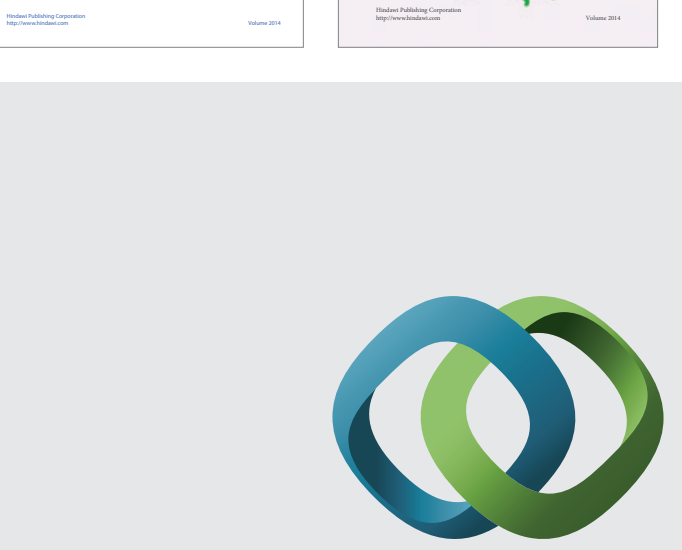

\section{Hindawi}

Submit your manuscripts at

http://www.hindawi.com
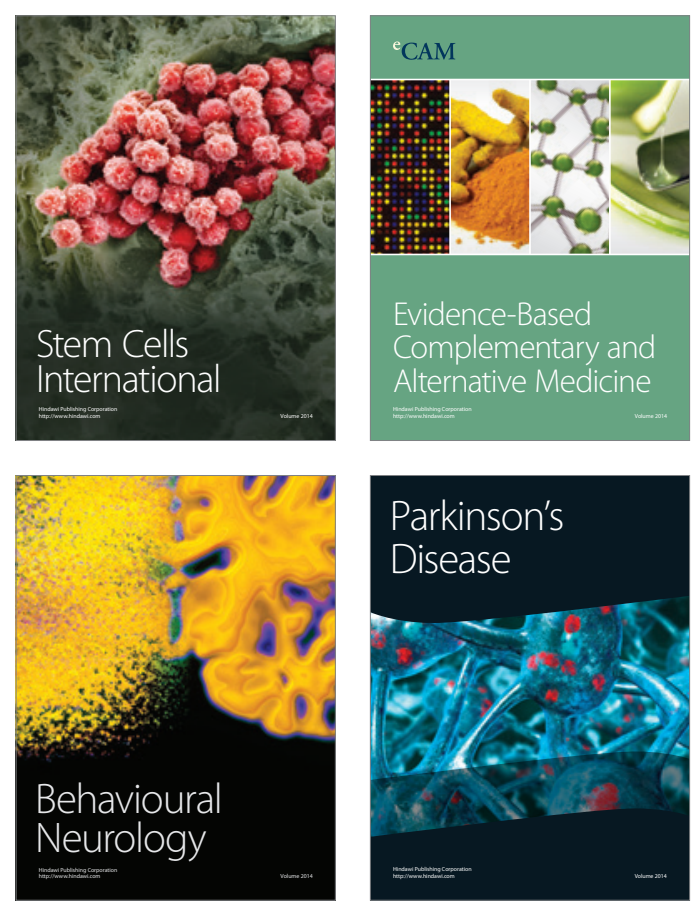

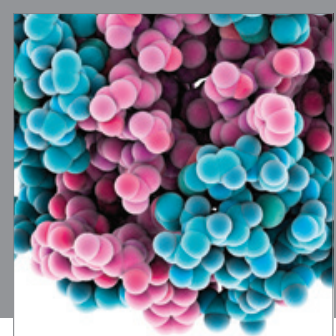

Journal of
Diabetes Research

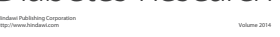

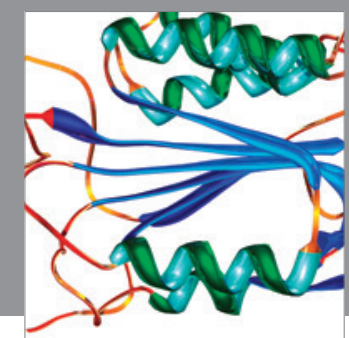

Disease Markers
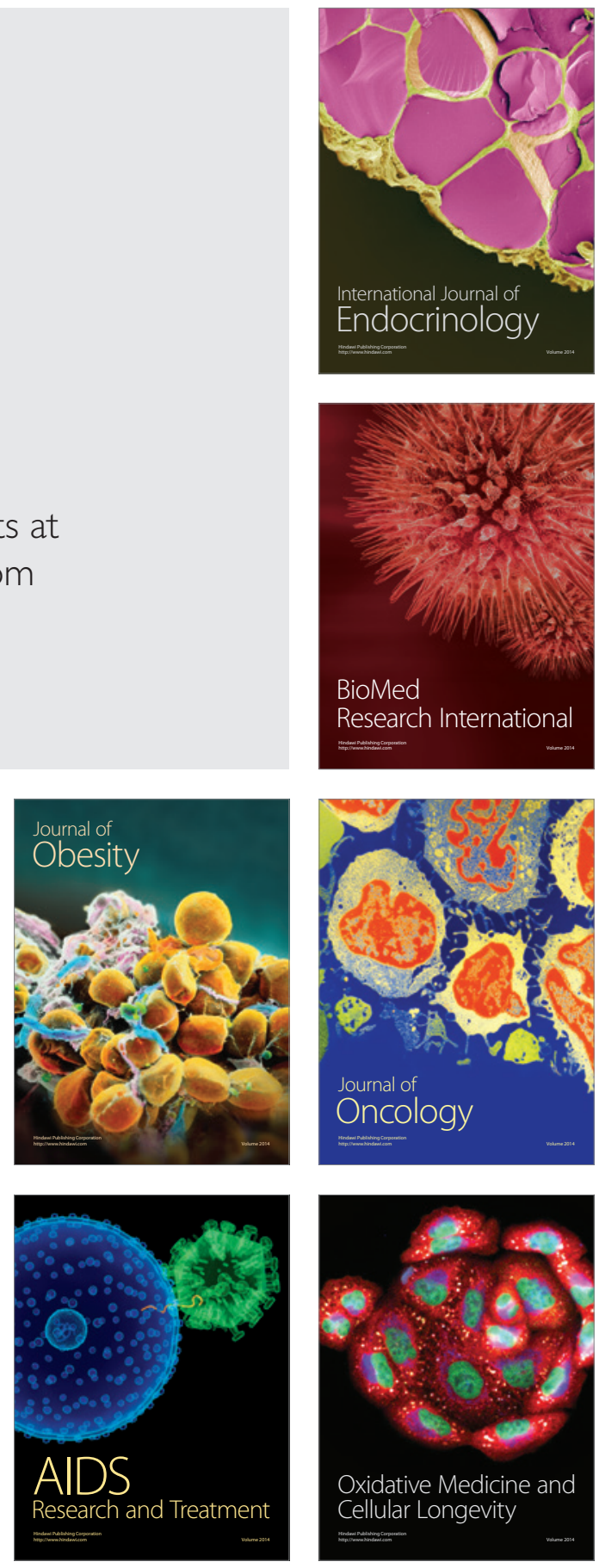